\title{
Late Pleistocene, Holocene and present sea-levels: constraints on future change
}

\author{
Kurt Lambeck \\ Research School of Earth Sciences, Australian National University, Canberra, ACT 2601, Australia
}

(Received by publisher July 30, 1990)

\begin{abstract}
Lambeck, K., 1990. Late Pleistocene, Holocene and present sea-levels: constraints on future change. Palaeogeogr., Palaeoclimatol, Palaeoecol. (Global Planet. Change Sect.), 89: 205-217.

Late Pleistocene and Holocene sea-levels exhibit considerable temporal and spatial variation around the globe when compared with present-day sea-levels. This is the result of volumetric changes of the ocean produced by the melting of the Pleistocene ice sheets, the response of the crust to these redistributed surface loads, and to tectonic movements of the shore lines of other than glacio-hydro-isostatic origin. By examining the sea-level records from geographically well-distributed areas over time spans covering the past 10,000 years, and by avoiding records from tectonically unstable regions, it becomes possible to effect a separation of the major parameters contributing to the sea-level change. Geomorphological observations of sea-level change at sites far from the former ice sheet margins provide constraints on the total volume of Late Pleistocene meltwater and on the rate at which this meltwater has been added into the oceans. The Laurentide and Fennoscandian ice sheets appear to have been inadequate to explain the observed sea-level rise of about $130 \mathrm{~m}$ from 18,000 to 6000 years ago. Some contribution $(\simeq 10-15 \mathrm{~m})$ from the Barents-Kara seas may have occurred as well. Antarctic contributions to the rise in sea-level appear to have been important and occurred at about the same time as or slightly after the Arctic ice sheet decay. The Antarctic melting continued, at slow rates, up to the present.

Tide gauge records over the past few decades also exhibit spatial variations in the rates of increase. The global average is about $1.2 \mathrm{~mm} /$ year but a pronounced zonal variation also occurs. About $50 \%$ of the global average rise may be the result of on-going melting of mountain and Antarctic glaciers and part of the spatial variation is the result of the ongoing glacial rebound. The long-wavelength spatial variation suggests that surface warming occurs in equatorial regions at a faster rate than middle and high latitudes and that Pacific-Indian Oceans warming occurs at a faster rater than the Atlantic Ocean.
\end{abstract}

\section{Introduction}

Evidence for temporal fluctuations in sea-level abounds in the geological record, particularly for Late Pleistocene and Holocene time. These observations have significance for solid-earth geophysics, oceanography, glaciology, climatology and tectonophysics, and while the emphasis of this conference is primarily on the climatological aspects, the others cannot be ignored because of the nature of the observations themselves and because of the interaction of the various processes involved. The observations of sea-level change are observations of changes in relative position between the crust and the ocean surface. Such change may, therefore, be indicative of fluctuations in the volume of the ocean waters or of tectonic movements of the crust relative to the Earth's centre of mass. Until the tectonic movements can be measured with high accuracy, independent of the sea-level reference surface, as is now possible with the methods of geodesy based on space technology (e.g. Lambeck, 1988), a separation of the two parts of the problem is possible only if certain model assumptions are made.

Volumetric change in the ocean are of two types, usually referred to as eustatic and steric. 
The eustatic rise of sea-level is the result of water being added to or subtracted from the oceans, mainly through an exchange with ice held in the polar ice caps, or, on a longer geological scale, by changes in the shape of the ocean basins. The steric effects refer to changes in sea-level produced by changes in water density. Neither the steric nor the eustatic sea-level changes are constant over the globe because of the Earth's non-uniform response to variations in surface loading or because of the ocean's long mixing time constants. The eustatic and steric effects have one important difference in that the first produces changes in the mass distribution and hence has a gravitational potential signature, whereas the second produces only second-order and negligible changes in the gravitational potential. Hence some separation between the two contributions is possible from geodetic observations of changes in the Earth's shape or in the planet's rotation (e.g. Peltier, 1988).

In order to understand the basis for predicting future sea-level patterns in response to climatic fluctuations, it is important to understand past and present trends in sea-level. The Late Pleistocene observations of sea-level are important for establishing the magnitude of the exchange of mass between the polar ice sheets and the oceans that has occurred through time. Observations of Holocene sea-level are important for establishing the rates at which this exchange has occurred during the latest collapse of the Late Pleistocene ice sheets and for examining the role of the Antarctic ice sheets. The study of these past signals are important for testing model hypotheses and for establishing model parameters. Observations of the presentday sea-level change are important for establishing whether these trends are the consequences of past processes or whether they are indicative of anthropogenic processes.

It is not the intent to review the subject in detail here. Instead, I wish to highlight certain recent results that appear to be relevant to the question of how sea-level may respond to future climatic change. Many of the results are preliminary and more indicative of the research that still needs to be done than of hard facts.
The present global pattern of sea-level change

It is usual to quantify secular sea-level change by a single parameter, a global average rise in sea-level (equal to the change in ocean volume divided by ocean surface area). Sea-level, once oceanographic and meteorologic forcing is eliminated, is an equipotential surface whose shape is determined by the mass distribution within the Earth as well as the self-attraction by the ocean water and ice sheets. As a result, when water is transferred from the ice caps to the oceans, the ocean rise is not necessarily uniform as the equipotential surface is modified by the new distribution of surface mass. Furthermore, the Earth deforms under the redistribution of this load and the final ocean surface takes on a quite complex shape. By 6000 years ago, for example, the melting of the Late Pleistocene ice sheets was largely complete and the then sea-level would on average be equal to the present-day sea-level. Yet regionally, sealevels at that period ranged by $100 \mathrm{~m}$ or more above their present levels at sites near the margins of the Late Pleistocene ice sheets up to $10 \mathrm{~m}$ below their present level elsewhere. Analyses of secular sea-level change in terms of a single parameter are therefore incomplete representations of secular sea-level change. As well, they may be unreliable because, in the presence of incomplete global sampling, the estimates are functions of the locations of the sampling sites.

Most of the more reliable tide-gauge records of durations longer than a few decades are from northwest Europe, the Atlantic coast of North America and Japan, regions that are subject to a rebound of the crust in response to Late Pleistocene and Early Holocene deglaciation or, in the case of Japan, a region that is tectonically unstable. Elsewhere, the tide-gauge records are more sparsely distributed, are of shorter record, and sometimes less reliable. The estimation of global trends of sea-level change is therefore fraught with difficulty yet, because the situation will not change for several decades, a necessary one.

A number of analyses suggest that the global 
rise is about $1.0-1.5 \mathrm{~mm} / \mathrm{yr}$ (Barnett, 1983; Emery, 1980; Gornitz et at., 1982) but only S.M. Nakiboglu, K. Lambeck and S. Hekiboglu have attempted to establish the regional pattern of this change. The essentials of the method employed are: (1) estimate secular rates by removing quadratic and long-period tidal and meteorological signals from the individual tide-gauge records; (2) establish average trends for the secular rates for $30^{\circ} \times 30^{\circ}$ rectangular areas of the ocean using statistical methods that have been widely used in estimating global gravity fields from incomplete data sets; (3) expand the area mean secular rates into a spherical harmonic expansion incorporating covariance analyses. Figure 1 illustrates the resulting pattern of secular rates. Only harmonics of low degree $(n \leqslant 2)$ are stable. This approach to the analysis reduces giving excessive weight to regions containing large numbers of tide gauges and reduces the effects of local and regional tectonics. At some sites quadratic trends have been identified, but only at about $20 \%$ of the records exceeding fifty years is this acceleration significant. Overall, the present results are not able to support or reject arguments for an accelerating rate of sea-level rise and secular rates may be taken to be nearly constant for the observation period.

The zero degree coefficient in the expansion $\left(\overline{\mathrm{C}}_{001}\right.$ in Table 1$)$ is the most significant one and corresponds to the globally averaged secular rise
TABLE I

Normalized spherical harmonic coefficients $C_{n m i}$ of the secular sea-level change where $n$ is the degree, $m$ the order and $i$ indicates the sine $(i=1)$ or cosine $(i=2)$ term. Units are in $\mathrm{mm} /$ year

\begin{tabular}{lrccc}
\hline & Observed & $\begin{array}{l}\text { Mountain } \\
\text { glaciers }\end{array}$ & $\begin{array}{l}\text { Arctic- } \\
\text { Antarctic }\end{array}$ & Residual \\
\hline $\mathrm{C}_{001}$ & $\mathbf{1 . 1 5} \pm 0.38$ & 0.36 & 0.22 & 0.57 \\
$\mathrm{C}_{101}$ & $-0.14 \pm 0.30$ & -0.09 & -0.14 & 0.09 \\
$\mathrm{C}_{111}$ & $0.07 \pm 0.27$ & -0.06 & -0.01 & 0.14 \\
$\mathrm{C}_{112}$ & $0.24 \pm 0.26$ & -0.02 & -0.12 & 0.37 \\
$\mathrm{C}_{201}$ & $-0.86 \pm 0.25$ & -0.07 & -0.02 & -0.77 \\
$\mathrm{C}_{211}$ & $-0.01 \pm 0.23$ & -0.01 & -0.01 & 0.01 \\
$\mathrm{C}_{212}$ & $-0.54 \pm 0.23$ & -0.03 & 0.02 & -0.56 \\
$\mathrm{C}_{221}$ & $0.12 \pm 0.20$ & 0.02 & -0.02 & 0.12 \\
$\mathrm{C}_{222}$ & $0.27 \pm 0.21$ & -0.01 & -0.00 & 0.28 \\
\hline
\end{tabular}

in sea-level. Its value of $1.15 \pm 0.38 \mathrm{~mm} / \mathrm{yr}$ is consistent with the early estimates of R. Fairbridge and $\mathrm{B}$. Gutenberg and with the more recent estimates of Gornitz et al. (1982) and Barnett (1983), but significantly less than the estimate of $3.0 \mathrm{~mm} / \mathrm{yr}$ by Emery (1980). Because the records from the majority of the tidegauge stations do not extend far back into time, this result is representative of the past 30 or 40 years rather than of the past 80 or 100 years, particularly because many of the recent stations lie in the more sparsely covered areas of the oceans and contribute correspondingly more to the $30^{\circ}$ area means.

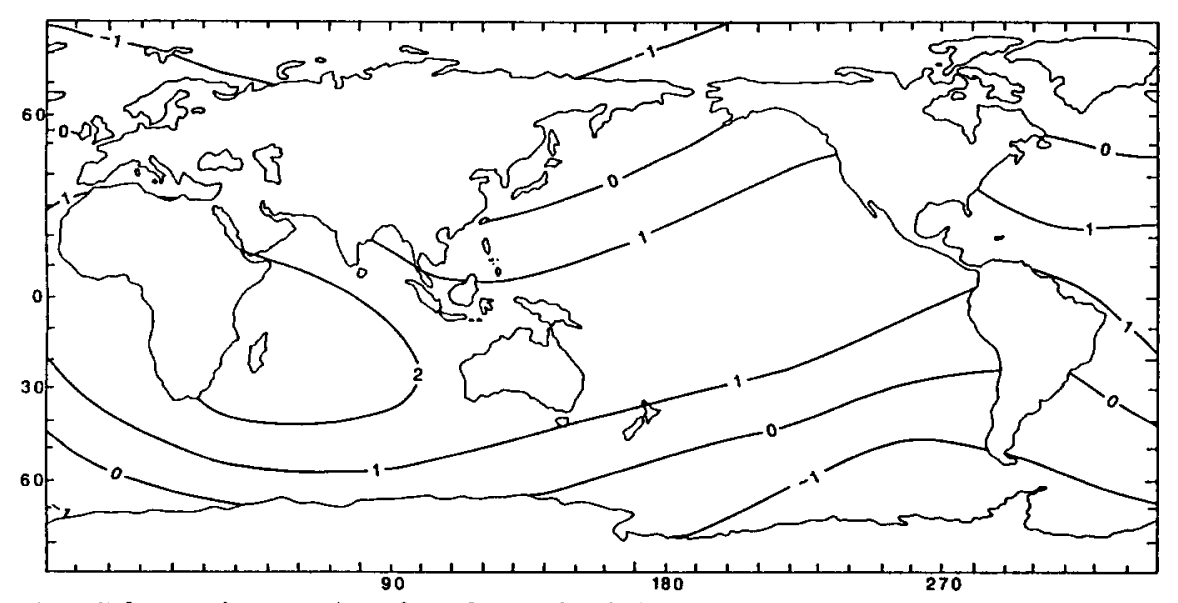

Fig. 1. Low degree $(n \leqslant 2)$ harmonic expansion of secular sea-level change for the past 30-40 years. Units are mm/year. 
Of the remaining coefficients it is the zonal term $\mathrm{C}_{201}$ that is significant and it implies an increase in the rate of sea-level rise in equatorial latitudes over the average value, and a lower than average sea-level rise in higher latitudes. Of the other second-degree coefficients in the expansion, possibly only the sectorial coefficient $\mathrm{C}_{212}$ (the sine term) is significant. The firstdegree coefficients are also small and insignificant, indicating that there is no overall shift in centre of mass of the oceans. From this, it can be inferred that either there is no appreciable melting of the polar ice caps or, if there is, that melting occurs concurrently in both the Arctic and Antarctic ice sheets so as to cancel the effects on the shift of the centre of mass. This latter interpretation is compatible with the observed zonal coefficient although the coefficient is also consistent with warming and thermal expansion of ocean water in equatorial and low latitudes. Sea-level data alone is inadequate to distinguish between the two causes and independent glaciological and climatological data are necessary as further constraints.

\section{Mountain glacier and Antarctic melting}

One possible contribution to the present sealevel rise is the melting of mountain glaciers which, while relatively small in volume, exhibit considerable variation in volume on time scales of several centuries, and which have generally been shrinking over the past century. Estimates of the globally averaged rate at which sea-level has risen in response to this melting are about 0.4-0.5 mm/yr (Lambeck, 1980, p. 295; Meier, 1984) but, like the adjustment of the ocean to the melting of the major ice sheets, the surface response to the shift of meltwater is not uniform. Using Meier's (1984) rates of mountain glacier melting and a non-rigid Earth, sea-level change is quite variable: it actually falls along coastlines near the major mountain glaciers of Alaska and the Patagonian Andes (Fig. 2). The Alaskan Gulf results are particularly interesting in that the tide-gauge records here are generally indicative of a falling sea-level. The global expansion of this contribution is dominated by the zero degree term but first and second degree harmonics are not wholly insignificant (Table 1) and contribute to the pattern deduced from the tide-gauge records.

Whether the Antarctic ice sheet continues to add meltwater from grounded ice sheets remains a matter of some debate. Meier et al. (1985) concluded, on the basis of tenuous evidence, that the Antarctic ice sheet may be accreting, producing a fall in sea-level of $-0.6 \pm 0.4 \mathrm{~mm} / \mathrm{yr}$ but studies of iceberg discharge of Antarctica suggest that rates of calving have been underestimated (Orheim, 1984). Shabtaie and Bentley (1987), however, suggest that the grounded ice of

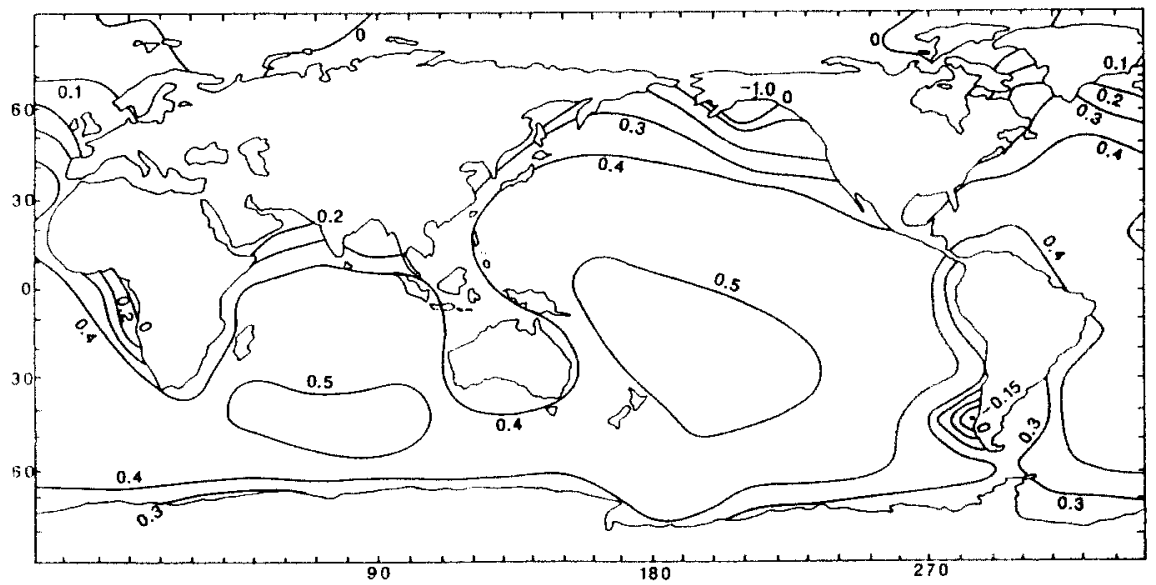

Fig. 2. Variation in sea-level resulting from the mountain glacier melting model of Meier (1984). Units are in $\mathrm{mm} / \mathrm{year}$. (The contour interval for the negative values near Alaska is much larger than elsewhere.) 


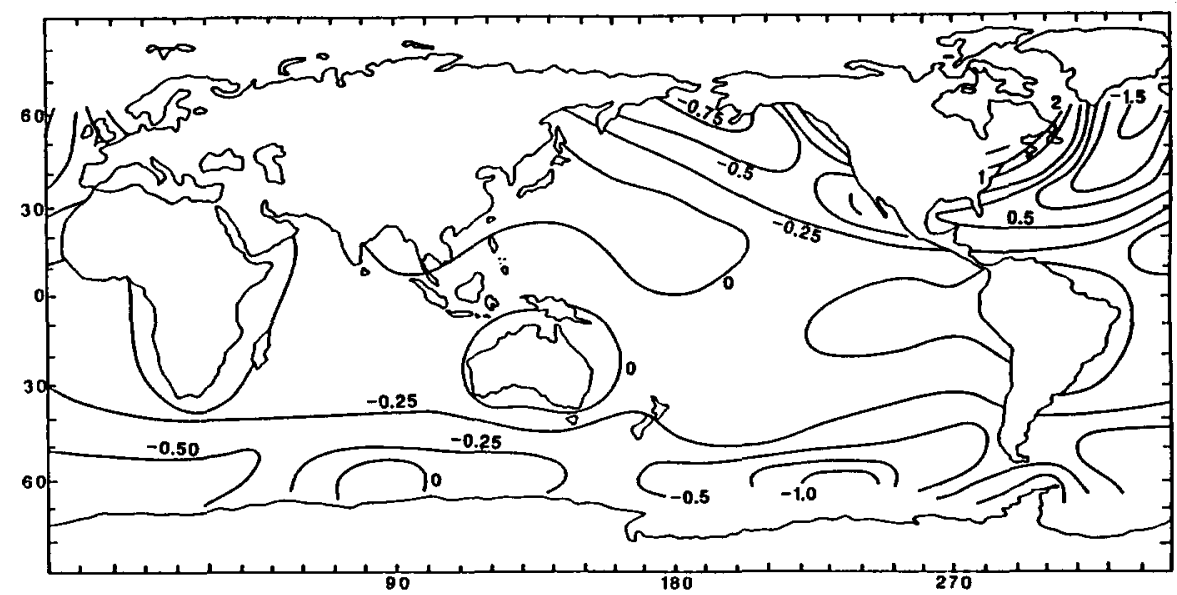

Fig. 3. Variations in sea-level resulting from the Late Pleistocene and Holocene deglaciation of the Arctic and Antarctic ice sheets according to the model of Nakada and Lambeck (1988a). (Units in mm/year.)

the Ross Ice Shelf is retreating at a rate that would produce a rise in sea-level of $0.1 \mathrm{~mm} / \mathrm{yr}$. Recent ice retreat in the Vestfold Hills of Antarctica also suggest on-going melting (Adamson and Pickard, 1986). Independent, but not unambiguous, evidence for melting of the Antarctic ice sheet during the Late Holocene comes from a study of Late Holocene high-stands (see below).

Figure 3 illustrates the estimates of the present-day sea-level change resulting from both the on-going rebound of the Earth to the Late Pleistocene-Early Holocene deglaciation and an on-going but very slow melting of the Antarctic ice sheet using the model of Nakada and Lambeck (1988a). Of note are the significant changes occurring along the Atlantic coast of North America and northwest Europe, at rates equal or greater than the present-day global secular rates. The low degree coefficients of the spherical harmonic expansion of this contribution are given in Table 1. The contribution to the average sea-level rise in this model is 0.2 $\mathrm{mm} / \mathrm{yr}$ and may be too high, although it is consistent with the assumption that the Vestfold Hills observation is characteristic of the

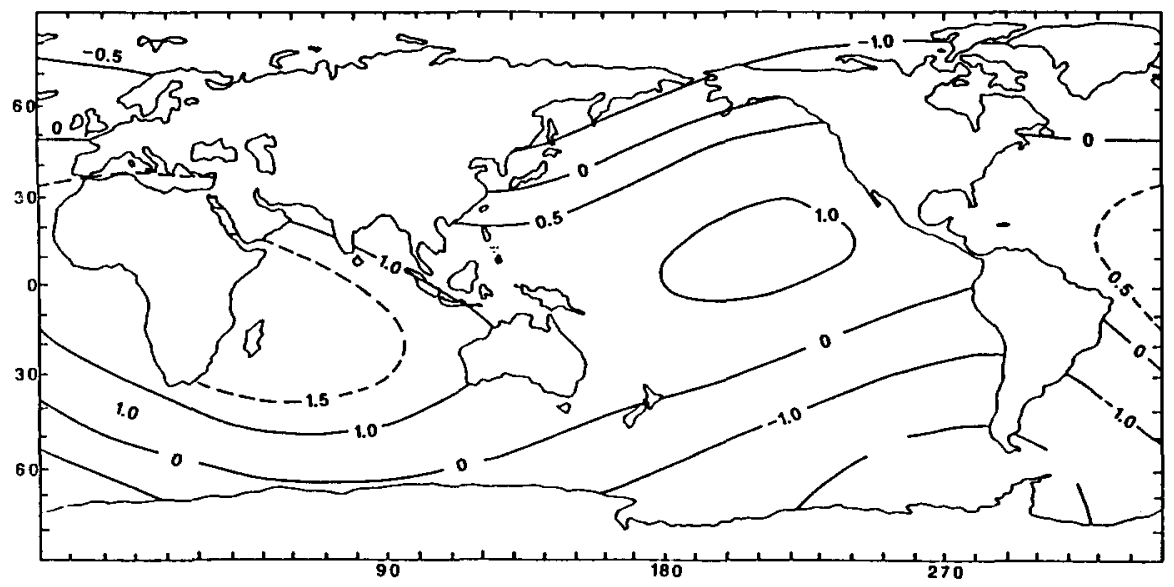

Fig. 4. Observed sea-level change (Fig. 1) corrected for the long wavelength contributions from deglaciation (Figs. 2 and 3 ). 
entire Antarctic ice sheet. The small predicted centre-of-mass offset $\left(C_{101}\right)$ equals the observed value.

\section{Steric sea-level change}

Table 1 summarizes the long-wavelength components of the contributions from the melting of the mountain and Antarctic glaciers and the rebound of the crust to the Late Pleistocene, Holocene and present redistribution of the meltwater into the oceans. The residual coefficients, the difference between the observed and these predicted contributions, could, with caution, be interpreted as the change in steric sealevel. The average global steric sea-level rise is about $0.6 \mathrm{~mm} / \mathrm{yr}$ although the uncertainty in this quantity is large, reflecting both observational and meltwater uncertainties. Some of the spatial variation in the steric sea-level is more significant (Fig. 4). The dominant term is the zonal pattern, with the equatorial and mid-latitude oceans experiencing a rise of $1-2 \mathrm{~mm} / \mathrm{yr}$ compared with a fall of $1 \mathrm{~mm} / \mathrm{yr}$ in high latitudes although the $\mathrm{C}_{212}$ coefficient may also be significant. Little of this long-wavelength spatial variation can be attributed to the eustatic factors (Table 1) and the result suggests that Pacific equatorial waters have been warmed by greater amounts than mid- and high latitude oceans, and that temperature rises in the Atlantic have generally been less than in the Pacific Ocean.

Assuming that only the upper $100-200 \mathrm{~m}$ of ocean responds to surface warming on a short timescale, the implied changes in water temperature are of the order of $0.025-0.05^{\circ} \mathrm{C}$ per $\mathrm{mm}$ of sea-level change, very similar to those observed in the Atlantic (Wahl and Bryson, 1975). Gornitz et al. (1982) examined the correlation between decade-scale global near-surface atmospheric temperature $T$ and sea-level $\zeta$ fluctuations and obtained $\zeta=160 T \mathrm{~mm} / \mathrm{yr}$ where $T$ is in ${ }^{\circ} \mathrm{C} / \mathrm{yr}$. An analysis of global near-surface atmospheric temperature variations by Jones et al. (1986) indicated an overall increase of about $0.005^{\circ} \mathrm{C} / \mathrm{yr}$ for the past 120 years so that the expected sea-level rise is about $0.8 \mathrm{~mm} / \mathrm{yr}$, consistent with the above analysis.

\section{Holocene sea-level change}

Observations of sea-level change during the Holocene period are important for defining the Earth-response and the bulk melting characteristics of the ice sheets, functions that are important for quantifying the present-day sea-level change. Hence, the study of the Holocene sealevel variations is a critical part of understanding present and future change. In such studies it is important to recognize that by examining the spatial and temporal variation of sea-levels in the Holocene it becomes possible to separate out the various parameters that quantify the relative motions between the crust and ocean surface.

\section{Late Holocene high-stands}

The sea-level changes over the past $6000-7000$ years are sensitive indicators of both the Earth's response to variations in surface loading and to changes in ocean volume. The characteristic change observed at continental sites far from the ice sheet is a rapid rise in sea-level up to about 6000 years ago, culminating in a highstand of 1-2 $\mathrm{m}$ above the present level, followed by a nearly uniform drop up to the present. Spatial variations in the amplitude of this maximum (Fig. 5) and in its timing occur from site to site and are a function of the geometry of the coastline (of the distribution of the added ocean water in the vicinity of the site), of the rate at which meltwater is added into the ocean, and of the mantle response to this ocean-water load. In particular, the Holocene high-stand amplitudes vary significantly between bays and gulfs on the one hand and open coastline on the other. Also, the amplitudes and time of occurrence of these high-stands is a function of the distance away from the coastline. These results mean that models of sea-level change must incorporate very high resolution descriptions of the coastline geometry (Nakada and Lambeck, 1987) and, in some instances, of the time dependence of this geometry (Nakada and Lambeck, 1989). Differential spatial variations in sea-level at these margin sites are relatively insensitive to the 

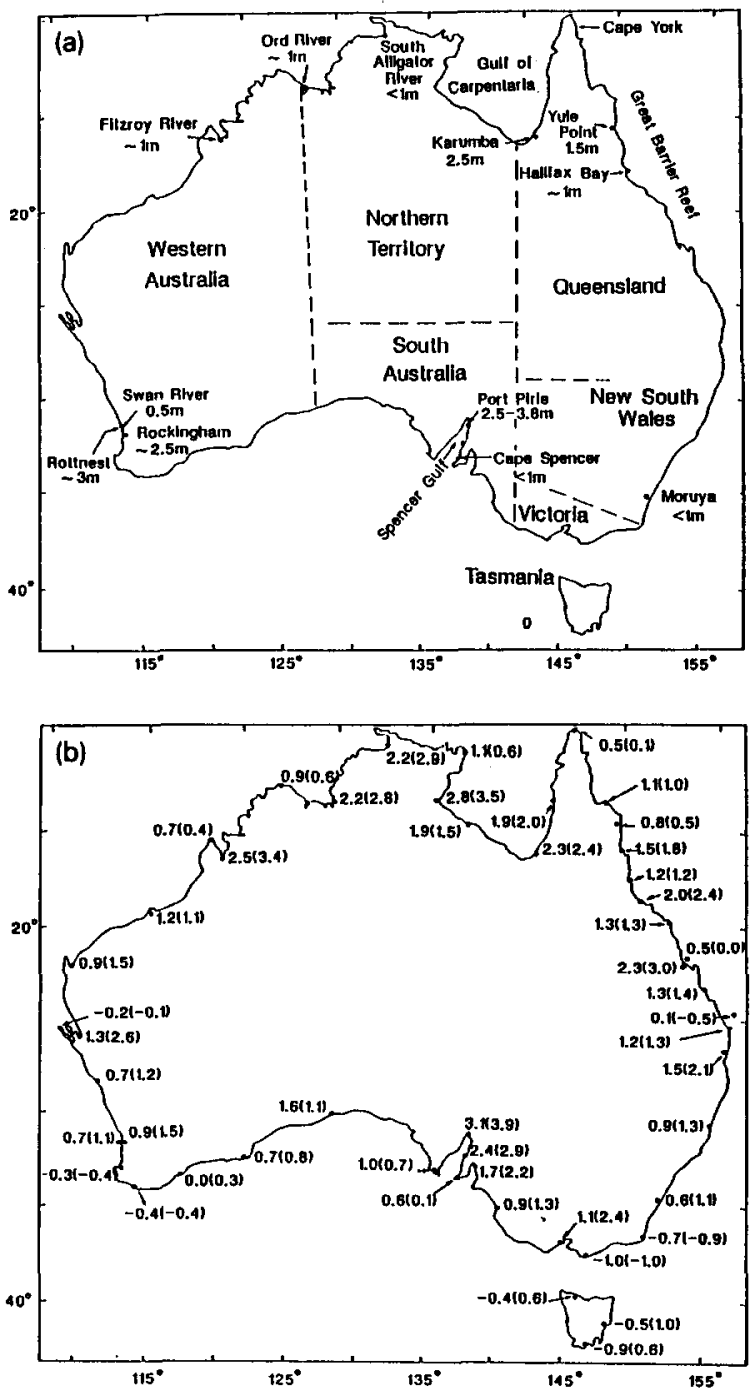

Fig. 5. (a) Summary of observed Holocene high-stands along the Australian coastline (see Nakada and Lambeck, 1988b). (b) Predicted high-stands at 6000 years ago based on two models of Nakada and Lambeck (1988b). The first model has an upper mantle viscosity of $10^{20} \mathrm{~Pa}$ s and a lower mantle viscosity of $1022 \mathrm{~Pa} \mathrm{~s}$. The second model has an upper mantle viscosity of $2 \times 10^{20} \mathrm{~Pa} \mathrm{~s}$. Both models incorporate Antarctic melting, including on-going melting (of about 2.5 $m$ equivalent sea-level rise) during the past 6000 years (Model ANT3a, Fig. 8).

choice of melt-models and observations of such variation are important for establishing the parameters that define the Earth's response to surface loading. The absolute amplitudes of the high-stands can then be used to constrain the bulk melting models of the ice sheets. A satisfac- tory agreement with the observations is reached if the Antarctic deglaciation did not cease at 6000 years ago but continued slowly since then, adding a further $2-3 \mathrm{~m}$ to the equivalent sealevel rise (see Nakada and Lambeck, 1988).

At oceanic islands, far from the ice sheets, the characteristic Late Holocene sea-level curve is a rather small amplitude ( $<1 \mathrm{~m}$ ) maximum occurring between about 4000 and 2000 years ago. Differential values of these maxima from nearby islands of different dimensions are sensitive to the Earth-response parameters while the timing of occurrence of these maxima is also sensitive to the meltwater model (Nakada and Lambeck, 1988b). Late Holocene sea-levels at sites near the ice sheet are distinctly different from those in the far-field because they are more strongly influenced by the unloading of the crust by the ice sheet than by the loading of the meltwater (Peltier and Andrews, 1976; Wu and Peltier, 1983). Hence, these observations are more important for constraining the melting history of the ice sheets than for estimating the Earth's response parameters.

\section{Early Holocene sea-level rise}

Observations of the rapid rise in sea-level between about 12,000 and 6000 years ago are important for establishing the rates and times at which the meltwater was added into the oceans. Particularly important are observations at sites away from the ice sheet where the sea-level changes are relatively insensitive to both the Earth-response parameters and to the detailed distribution of the ice load but are sensitive to the bulk-melting parameters. An examination of such records along Australian and Pacific coastlines indicate that the rise in sea-level in this interval is considerably greater in amplitude than can be attributed to models of Laurentide and Fennoscandia ice sheets alone. Additional meltwater is required, equivalent to a sea-level rise of more than $20 \mathrm{~m}$, at between 10,000 and 6000 years ago and which was added to the oceans at about the same rate as that originating from the northern ice sheets or possibly somewhat later. Figure 6 illustrates the observed 

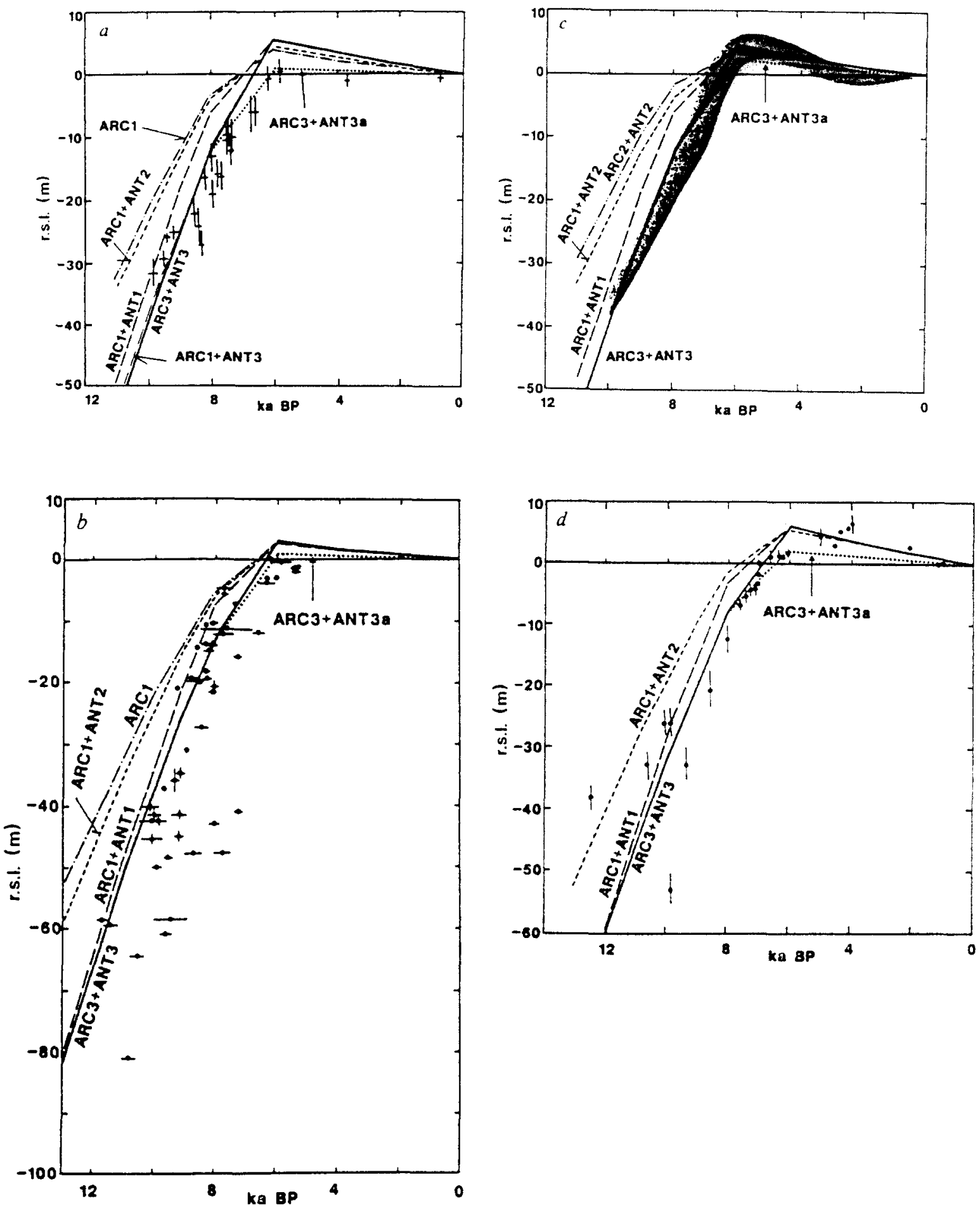

Fig. 6. Observed and predicted sea-levels at four sites in the far-field for different melting models (from Nakada and Lambeck, 1988). (a) Christchurch, New Zealand; (b) New South Wales, Australia; (c) Japan; (d) Malacca Straits. The equivalent gea-level curves for the various melt models (ARC, ANT) are illustrated in Fig. 8. 
and predicted sea-levels at four sites in the farfield for a number of melting models discussed by Nakada and Lambeck (1988). Note that the models ARC1 and ARC2, based on the northern ice model of Peltier and Andrews (1976), result in a major underestimation of the sea-level change in the interval up to 6000 years ago and there is a need to add considerable meltwater from other sources, ranging from about $25 \mathrm{~m}$ equivalent sea-level (e.s.l.) at 12,000 years ago to $9 \mathrm{~m}$ e.s.l. at 8000 years ago. This missing meltwater cannot be attributed to the northern ice sheets. This is illustrated in Fig. 7 where predicted and observed sea-levels are given at two sites near the centres of the former Laurentide and Fennoscandian ice sheets. At these sites the sealevels are strongly dependent on the Earth's response to the glacial unloading and to the volumes of the ice sheets, and to produce satisfactory agreement between observation and theory it is actually required to reduce these ice volumes (Wu and Peltier, 1983). An increase in ice volume in the Barentz and Kara seas also does not explain the discrepancy because if extensive ice sheets existed here they would have melted at about the same rate as the Fennoscandian ice sheet and would have contributed little to the sea-level change in the far-field after about 10,000 years ago.

An Antarctic source is more likely and Nakada and Lambeck (1988) concluded that melting of this ice may actually have lagged behind the decay of the Arctic ice sheet. Further sea-level data for this period is required, particularly in the neighbourhood of the Antarctic ice sheet, but if this interpretation is sustained it is important in that it lends support to the hypothesis that the Antarctic ice sheets melted in response to the rising sea-level caused by the decay of the northern ice sheets (Stuiver et al., 1981; Budd and Smith, 1982). This is consistent with the earlier drawn conclusion that the addition of meltwater to the oceans continued after about 6000 years ago when melting ceased in the Northern Hemisphere.

\section{Late Pleistocene sea-levels}

At only a few sites do the sea-level records extend further back than about 10,000 years and the observations provide few constraints on the ice models before that time. One important exception to this is a constraint on the total volume of meltwater that can be obtained from the
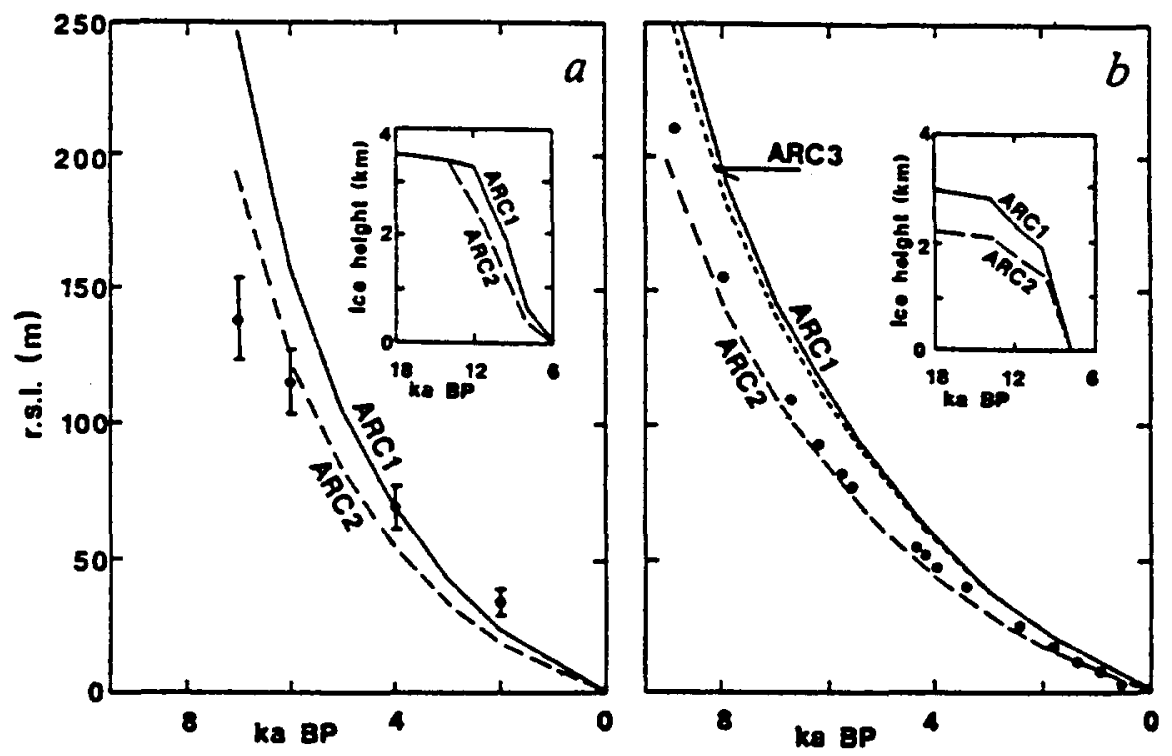

Figs 7. Same as Fig. 6 but for two sites near the centres of the Laurentide; (a) Cape Henrietta Maria and Fennoscandia; (b) Angermann River ice sheets respectively. The insets illustrate the melting of the ice sheets near the sites. 
minimum sea-levels at $18,000-20,000$ years ago. Generally these levels, well away from the ice sheets, were 115-150 m below the present level, with $130 \mathrm{~m}$ representing a 'reasonable' value (Chappell and Shackleton, 1986; Chappell, 1974, 1987, Yonekura and Ota, 1986). Regional variation in this level can be expected because of the Earth's response to surface loading and unloading and because of the need to keep the ocean surface an equipotential. For example, the models that predict between about 120 and $140 \mathrm{~m}$ in the Australian and Japan regions predict about $100 \mathrm{~m}$ along the southern and eastern coast of the United States. The northern ice sheets widely used in modelling of crustal rebound are generally inadequate to explain such magnitudes. Table 2 summarizes some results. The model ARC1 is from Peltier and Andrews (1976) and is, for this purpose, equivalent to their ICE1 model. ARC2 (their ICE2) represents an adjustment of ICE1, designed to give better agreement between theory and observation sites near the edge of the former northern ice sheet. ARC3 comprises ARC2 and a schematic ice model for the Barents and Kara Seas which adds a further $15 \mathrm{~m}$ to sea-level at the same time as the Fennoscandia ice model. (Because no observations near this ice sheet are used, only an approximate model is required.) The $59 \mathrm{~m}$ e.s.l. for the Laurentide ice in these models compares with 62-78 m estimated by Denton and Hughes (1981) for their minimum ice model reconstruction and with 77-93 $\mathrm{m}$ for their maximum ice model. The latter value approaches that required to explain the sea-levels at 18,000-20,000 years ago but unless this excess ice melted at an early stage, before about 12,000 years ago, it destroys agreement with the observations at sites within and near the margin of the ice sheet. This would favour models in which the Arctic ice sheets melted in two phases, the first between 16,000 and 13,000 years ago and the second between 10,000 and 8000 years ago (e.g. Duplessy et at., 1981). However, this model does not explain the sea-levels in the far-field in the period up to 6000 years ago and the preferred interpretation is that the missing meltwater originated from Antarctica. A specific model used by Nakada and Lambeck $(1988,1989)$ is based on the difference between the maximum Late Pleistocene reconstruction of Denton and Hughes (1981) and the present ice thickness mapped by Drewry (1982). This results in a further e.s.l. of $37 \mathrm{~m}$ and this now leads to good agreement with the sealevels at 18,000-20,000 years ago. Figure 8 illustrates the equivalent sea-level rise from the major ice sheets for the past 18,000 years as deduced from the sea-level observations during this interval.

Another important Late Pleistocene sea-level observation is the position of sea-level during the major glacial minimum at about 120,000 years ago when sea-levels are believed to have been several metres above their present level (e.g. Veeh, 1966; Ku et al., 1974). This represents a significant bench mark for distinguishing be-

TABLE II

Sea-level equivalents (metres) of the contributions of the Late Pleistocene ice sheets

\begin{tabular}{|c|c|c|c|c|c|}
\hline & \multirow[t]{2}{*}{ ARC1 } & \multirow[t]{2}{*}{ ARC2 } & \multirow[t]{2}{*}{ ARC3 } & \multicolumn{2}{|c|}{ From Denton and Hughes (1981) } \\
\hline & & & & $\min$. & $\max$. \\
\hline Laurentide & \multirow{2}{*}{59.0} & \multirow{2}{*}{57.2} & \multirow{2}{*}{59.0} & 75.6 & 84.8 \\
\hline Cordillera & & & & 0.7 & 4.6 \\
\hline Greenland (including Innuitian + Iceland) & 2.7 & 2.7 & 2.7 & 0.8 & 9.4 \\
\hline Scandinavia (including British Isles) & 15.1 & 11.5 & 15.1 & 19.4 & 20.1 \\
\hline Barents-Kara & 0.7 & 0.7 & 15.4 & 2.1 & 15.5 \\
\hline Mountain glaciers & & & & 4.5 & 3.2 \\
\hline \multirow[t]{2}{*}{ Total (Northern Hemisphere) } & 77.5 & 72.1 & 92.2 & 103.1 & 137.6 \\
\hline & ANT1 & ANT2 & ANT3 & & \\
\hline Antarctica & 37.1 & 37.1 & 37.1 & 24.3 & 24.3 \\
\hline
\end{tabular}




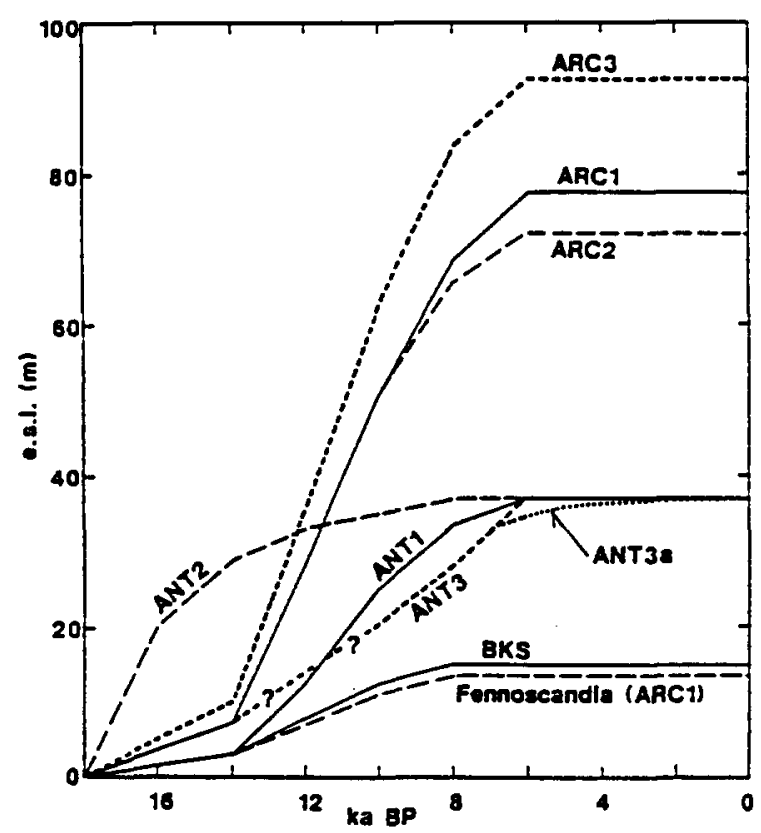

Fig. 8. Equivalent sea-level rise resulting from the melting of the combined Laurentide and Fennoscandia ice sheets ( $A R C 1$ and $A R C 2$ ), the Fennoscandia ice sheet only, the Barents and Kara ice sheet (BKS), $A R C 3=A R C 1+B K S$, and Antarctica ( $A N T 3 a$ ). In ANT2 melting occurs before the Arctic melting. $A N T 1$ is in phase with the Arctic melting and ANT3 lags behind the Arctic melting in the interval $12,000-6000$ years ago. $A N T 3 a$ incorporates on-going Late Holocene melting.

tween tectonic change and sea-level change for where these interglacial benchmarks are found to lie at more than a few metres from the present sea-level, tectonic movement may have been significant. Also, where these markers can be identified, it becomes possible to correct for the tectonic effect (e.g. Chappell, 1974).

The last interglacial sea-level is important for understanding the possible limits on future Antarctic deglaciation. The general scenario of the enhanced 'greenhouse' effect on sea-level may be sketched out in the following terms (e.g. Budd, 1988). A $4^{\circ} \mathrm{C}$ atmospheric warming will produce substantial increases in the melt rates in the Antarctic and lead to a removal of the large floating ice shelves within about $50-100$ years. This does not lead to a sea-level change, other than that produced by thermal expansion of the upper $100-200 \mathrm{~m}$ of the water column. However, the removal of the ice shelves, by removing the buttresses of the grounded ice, increases the strain rates within the ice sheets and allows more rapid glacier flow. In some models surges in glaciers of tens of kilometres per year have been postulated but rates of hundreds of metres per year may be more reasonable. The West Antarctic ice sheet has been identified as one area where rapid decay may occur on time scales of several hundred years (e.g. Lingle, 1984) raising sea-level by as much as 7 or $8 \mathrm{~m}$. Can observations of sea-levels during the Pleistocene present constraints on such scenarios?

During the last interglacial between about $120,000-140,000$ years ago, atmospheric and water temperatures are believed to have been somewhat higher than present-day values but the amount remains a matter of debate. The height of the last interglacial sea-level, relative to the Holocene high-stand, therefore provides an important measure of how the ocean responds to such a change in temperature. Estimates of the height of this high-stand vary from 2 to $9 \mathrm{~m}$ but in the tectonically stable regions of Australia, far from the ice sheets, the differential height of the Holocene and 120,000 year high-stands is only 1-2 $\mathrm{m}$ at most. In Western Australia the interglacial is at $3 \mathrm{~m}$ above sealevel, close to the Holocene high-stand. Along the southern margin of the continent it lies about $2 \mathrm{~m}$ above the Holocene and there is little evidence along the Queensland coast for an elevated interglacial sea-level. On the tectonically stabler islands such as Makatea, the differences between the Holocene and interglacial levels also appear to be only a few metres (Veeh, 1966). Only in locations such as Bermuda or Florida do the interglacial levels lie at a significant height above the Holocene but here rebound is still continuing in response to the latest deglaciation cycle and these sites may not be good indicators of differences in ocean volume at the two epochs.

The duration of the last interglacial is generally believed to have been about 10,000 years and in this time ocean mixing would be largely completed so that the temperature of the entire water column would have been raised in re- 
sponse to surface warming. Typically a $1^{\circ} \mathrm{c}$ temperature increase will produce about $1 \mathrm{~m}$ thermal expansion in mid-ocean so that the interglacial sea-levels do not support major average global temperature differences between today and 120,000 years ago. Also, there appears to be little evidence that significant deglaciation of the western Antarctic ice sheet occurred. Instead, this ice sheet may be relatively stable in the presence of global temperature increases of a few degrees.

\section{Conclusions}

Sea-level variations observed since Late Pleistocene time contain a wealth of information on the Earth's rheology, on the last deglaciation cycle and on vertical tectonics. By a careful examination of the record, by examining the spatial and temporal variations in the sea-level fluctuations and by using differential methods, it becomes possible to separate out these various effects. Much remains to be done, but from a preliminary examination of the data the following indicative conclusions can be drawn. (1) The total amount of land ice released from the Late Pleistocene ice sheets after about 18,000 years ago raised sea-level by about $130 \mathrm{~m}$ on average. The depth of this glacial maximum low stand will vary over the globe. (2) A significant part of this (possibly as much as $30-40 \mathrm{~m}$ ) is likely to have come from Antarctica and possibly 10-15 $m$ from the Barents and Kara ice sheets. (3) The Antarctic melting occurred at about the same time as the Arctic ice sheet decay and may even have occurred up to about 1000 years later. (4) The Antarctic melting did not cease at 6000 years ago but continued up to the present with about 2-3 $\mathrm{m}$ of sea-level rise occurring in the past 6000 years. (5) Present-day secular sea-level rise has a global average of about $1.2 \mathrm{~mm} / \mathrm{yr}$, but a pronounced regional variation, of zonal character, occurs. (6) Nearly half of this observed secular rise can be attributed to the ongoing melting of the mountain glaciers and to a small Antarctic contribution. The remainder is consistent with thermal expansion of the upper $100-200 \mathrm{~m}$ of the ocean column and with ob- served near-surface warming. (7) The amplitude of the Late Pleistocene interglacial (at $\simeq 120,000$ years ago) above the Holocene high-stand provides a constraint on the magnitude of sea-level rise produced by global warming.

All of the above conclusions are debatable, being based on inadequate records of past and present sea-level. Other than improvements in modelling techniques, requirements include the following. (1) Improved global mapping of the various major sea-stands, including the interglacial of 120,000 years ago, the glacial maximum at 20,000-18,000 years ago, and the Holocene maximum at about 6000 years ago. (2) Improved mapping of regional fluctuations in the amplitude and time of occurrence of the Holocene high-stand to examine, for example, variations with distance from the coastline, variations with size of islands, and variations with coastal geometry. (3) Improved information on the time of rapid rise in sea-level up to about 6000 years ago.

Of considerable importance is to have new information on all parts of the sea-level curve from sites near or on the edge of Antarctica. Also important are observations along longitude circles extending over large latitude bands, such as along the Indian Ocean coast of Africa, or the Atlantic coast of South America. Further information from tectonically stable islands in the Pacific and Indian Oceans is desirable.

The modelling of sea-level change requires further development as well, and the following are some areas for improvement. (1) Detailed descriptions of the coastlines are required in order to model the loading effect of meltwater with precision. In particular, in shallow seas, it is necessary to assume that these coastlines vary with time. (2) Improved rheological descriptions of the Earth are required. Current models assume linear, viscoelastic mantle models without lateral variations in physical properties. There is also an unresolved debate about whether adiabatic or non-adiabatic conditions should be used in the mantle (Cathles, 1975; Fjeldskaar and Cathles, 1984).

Another major area where improvements are in order is the modelling of the ice sheets. In 
particular, assumptions are made about the Earth's isostatic response to the ice loads that are generally inconsistent with the results obtained by geophysicists. Ideally, an integrated glaciological and geophysical model is required but iterative procedures may be adequate.

Much work requires to be done but the objectives are important not only for understanding some consequences of an enhanced greenhouse effect but also for understanding a variety of fundamental geophysical processes.

\section{References}

Adamson, D.A. and Pickard, J., 1986. Cainozoic history of the Vestfold Hills. In: J. Pickard (Editor), Antarctic Oasis. Academic Press, Sydney, pp. 63-93.

Barnett, T.P., 1983. Recent changes in sea-level and their possible causes. Climat. Change, 5: 15-38.

Budd, W.F., 1988. The expected sea-level rise from climatic warming in Antarctica. In: G.J. Pearman (Editor), Greenhouse: Planning for Climate Change. CSIRO, Melbourne, pp. 74-82.

Budd, W.F. and Smith, I.N., 1982. Large-scale numerical modelling of the Antarctic ice sheet. Ann. Glaciol., 3: 42-49.

Cathles, L.M., 1975. The Viscosity of the Earth's Mantle. Princeton Univ. Press, Princeton, NJ.

Chappell, J., 1974. Geology of coral terraces, Huon Peninsula, New Guinea: a study of Quaternary tectonic movements and sea-level changes. Geol. Soc. Am. Bull., 85: 553-570.

Chappell, J., 1987. Late Quaternary sea-level changes in the Australian region. In: M.J. Tooley and I. Shennan (Editors), Sea-level Changes. Blackwell, Oxford, pp. 296-331.

Chappell, J. and Shackleton, N.J., 1986. Oxygen isotopes and sealevel. Nature, 324: 137-140.

Denton, G.H. and Hughes, T.J. (Editors), 1981. The Last Great Ice Sheets. Wiley, New York, NY.

Drewry, D.J. (Editor), 1982. Antarctica: Glaciological and Geophysical Folio. Scott Polar Res. Inst., Cambridge.

Duplessy, J.C., Delibrias, G., Turon, J.L., Pujol, C. and Duprat, J., 1981. Deglacial warming of the northeastern Atlantic Ocean: correlation with the palaeoclimatic evolution of the European continent. Palaeogeogr., Palaeoclimatol., Palaeoecol., 35: 121-144.

Emery, K.O., 1980. Relative sea-levels from tide gauge records. Proc. Natl. Acad. Sci. U.S.A., 77: 6968-6972.

Fjeldskaar, W. and Cathles, L.M., 1984. Measurement requirements for glacial uplift detection of nonadiabatic density gradients in the mantle. J. Geophys. Res., 89: 10115-10124.

Gornitz, V., Lebedeff, L. and Hansen, J., 1982. Global sea level trend in the past century. Science, 215: 1611-1614.

Jones, P.D., Wigley, T.M.L. and Wright, P.B., 1986. Global temperature variations between 1861-1984. Nature, 322: 430-434.
Lambeck, K., 1980. The Earth's Variable Rotation. Cambridge Univ. Press, 449 pp.

Lambeck, K., 1988. Geophysical Geodesy: The Slow Deformations of the Earth. Oxford Univ. Press, $718 \mathrm{pp}$.

Lingle, C.S., 1984. A model of a polar ice stream and future sea-level rise due to possible drastic retreat of the West Antarctic Ice Sheet. In: Glaciers, Ice Sheets, and Sea Level: Effect of a $\mathrm{CO}_{2}$ Induced Climatic Change, Workshop Rep. DOE/ER/60235-1, Natl. Tech. Inf. Serv., U.S. Dep. Comm., Virginia, pp. 317-330.

Ku, T.-L, Kimmel, M.A., Easton, W.H. and O'Neil, T.J., 1974. Eustatic sea-level 120,000 years ago on Oahu, Hawaii. Science, 183: 959-962.

Meier, M.F., 1984. Contribution of small glaciers to global sea level. Science, 226: 1418-1421.

Meier, M.F. et al. (Editors), 1985 Glaciers, Ice Sheets, and Sea Level: Effect of a $\mathrm{CO}_{2}$-induced climatic change. Workshop Rep. DOE/ER/60235-1, Natl. Tech. Inf. Serv., U.S. Dep. Comm., Virginia.

Nakada, M. and Lambeck, K., 1987. Glacial rebound and relative sea-level variations: A new appraisal. Geophys. J., 90: 171-224.

Nakada, M. and Lambeck, K., 1988. The melting history of the Late Pleistocene Antarctic ice sheet. Nature, 333: 36-40.

Nakada, M. and Lambeck, K., 1989. Late Pleistocene and Holocene sea-level change in the Australian region and mantle rheology. Geophys. J., 96: 497-517.

Orheim, 0., 1984. Iceberg discharge and the mass balance of Antarctica. In: Glaciers, Ice Sheets, and Sea Level: Effect of a $\mathrm{CO}_{2}$ Induced Climatic Change, Workshop Rep. DOE/ER/60235-1, Natl. Tech. Inf. Serv., U.S. Dep. Comm., Virginia, pp. 210-215.

Peltier, W.R. and Andrews, J.T., 1976. Glacial isostatic adjustment-I: The forward problem. Geophys. J., 46: $605-646$.

Peltier, W.R., 1988. Global sea-level and Earth rotation. Science, 240: 895-901.

Shabtaie, S. and Bentley, C.R., 1987. West Antarctic ice streams into the Ross ice shelf: Configuration and mass balance. J. Geophys. Res., 92: 1311-1336.

Stuiver, M., Denton, G.H., Hughes, T.J. and Fastook, J.L., 1981. History of the marine ice sheet in west Antarctica during the last glaciation: A working hypothesis. In: G.H. Denton and T.J. Hughes (Editors), The Last Great Ice Sheets. Wiley, New York, NY.

Veeh, H.H., 1966. Ages of Pleistocene high sea level stands. J. Geophys. Res., 71: 3379-3386.

Wahl, E.W. and Bryson, R.A., 1975. Recent changes in Atlantic surface temperatures. Nature, 254: 45-46.

Wu, R. and Peltier, W.R., 1983. Glacial isostatic adjustment and the free air gravity anomaly as a constraint on deep mantle viscosity. Geophys. J., 74: 377-449.

Yonekura, N. and Ota, Y., 1986. Sea-level changes and tectonics in the Late Quaternary. Rec. Prog. Nat. Sci., Japan, Quat. Res., Sci. Counc. Jap, 11: 17-34. 